\title{
USING PILE SORTS TO UNDERSTAND PERCEPTIONS OF CLIMATE CHANGE
}

\author{
LYDIA R. HORNE, SANDRA DE URIOSTE-STONE, JOHN DAIGLE \& CAROLINE NOBLET \\ University of Maine, USA
}

\begin{abstract}
More research is needed to understand how the detection and attribution of climate change impacts and shapes stakeholder mitigation and adaptation behaviors in the tourism industry. Pile sorting has been a widely used method in anthropology and psychology, but few studies have used pile sorting to understand how people think about climate change risks. The goal of this study is to address these gaps in the literature by using pile sorting to understand group cognition of nature-based tourism stakeholders about climate change and how these perceptions influence mitigation and adaptation behaviors. We conducted the study in Western Maine, an area highly vulnerable to climate change due to the region's reliance on winter nature-based tourism. Participants were selected using chain referral. Pile sorts were embedded in nineteen semi-structured interviews. Participants were given 34 cards listing environmental and social conditions and asked to sort them using their own criteria for organization of piles. We used multidimensional scaling analysis in SPSS 24 to analyze the pile sorts and generate a spatial map depicting how terms were related. Transcripts were thematically coded to further understand pile names. Two dimensions emerged from the data: perceived control and drivers and impacts. Perceived control was low and terms in these piles were often acknowledged to be caused and influenced by humans, but participants felt that these issues were out of their control to mitigate or manage. Participants distinguished between drivers of climate change and resulting impacts to both the tourism and overall socio-ecological system. Understanding how nature-based tourism stakeholders in the study region understand climate change will help inform our interpretation of risk perceptions and behavioral responses to climate change. This knowledge will help tailor climate change communications to be more effective in building awareness, empowering stakeholders to mitigate and adapt in the face of climate change.

Keywords: risk perceptions, cultural domain analysis, nature-based tourism, winter tourism, multidimensional scaling analysis, adaptation.
\end{abstract}

\section{INTRODUCTION}

Given that perceptions can influence behavior, more research is needed to understand how people think about climate change to better understand their willingness to act [1]. Due to nature-based tourism's vulnerability to changing climate and its contribution to greenhouse gas emissions, research to understand detection and attribution of climate change impacts is important because these perceptions can drive adaptation and mitigation actions [2]. Vulnerability refers to the extent to which systems and individuals are susceptible to, and unable to cope with, climate change risks [3]. A tourism destination decreases their vulnerability to climate change by increasing capacity to respond to and influence change, thereby increasing resilience [4]. Tools from cultural domain analysis can help identify group cognition, while leading to a greater understanding of how tourism stakeholders frame climate change, and its effects.

\subsection{Cultural domain analysis and pile sorting}

A cultural domain is a set of things or items that are all in the same mental category where all items are alike in some important way [5], [6]. Pile sorts ask the question "What goes with what?" to understand group cognition of a cultural domain. Researchers use an emic approach 
by asking participants to sort cards into piles using the criteria that are most salient to determine similarity [7]. Despite the ease of administering the technique, pile sorting has rarely been used to understand how people think about climate change. A pile sort methodology has been used by several other authors to understand risk perceptions [8]-[9] but only one study has used pile sorting to understand group cognition of climate change [10]. We address this gap in the literature by incorporating a pile sort into interviews to understand how tourism stakeholders as a group think about climate change and how that group cognition attenuates or amplifies climate change risk perceptions.

\subsection{Detection and attribution of climate change impacts}

To respond to climate change, it is necessary to predict its impacts on natural and human systems [11]. From a social science perspective, it is important to understand how, if at all, people detect climate change effects and whether these observed/perceived impacts are being connected back to climate change. "Detection of impacts" of climate change addresses the question of whether a natural or human system is changing beyond a specified baseline that characterizes its behavior in the absence of climate change [11]. "Attribution" addresses the question of the magnitude of the contribution of climate change to a shift in a system [11]. Tourism is a climate sensitive economic sector; recent research efforts have focused on understanding its vulnerability to climate change and identifying the impacts of climate change on the system, yet few studies have focused on detection and attribution of observed impacts and resulting behavioral responses in the tourism industry [1], [12].

\subsection{Tourism and climate change in Maine}

Tourism is one of Maine's largest industries, supporting 16\% of state employment with 105,957 direct jobs [13]. In 2016, nearly 19 million tourists stayed one or more nights in Maine, spending nearly 6 billion USD [13]. Of those 19 million visitors, 35\% specified interest in outdoor activities, indicating that nature-based tourism is an important economic industry in Maine [14]. In 2015, nature-based tourists spent over 8.3 billion USD [15]. The nature-based tourism industry's economic importance in Maine and reliance on natural features makes it especially sensitive to the effects of climatic changes. In Maine, climate models predict higher average annual temperatures, longer summers and shorter winters, increases in precipitation, and decreases in snowfall [16]. These changes are expected to continue and perhaps worsen in the future, increasing vulnerability but also providing new development opportunities. Therefore, understanding how nature-based tourism stakeholders perceive their risk to climate change, ad their level of preparedness is important to cope with negative effects and take advantage of opportunities that might result for climatic changes. Our study is the first to assess stakeholder climate change risk perceptions in Maine in an attempt to understand detection and attribution of impacts to climate change.

\section{METHODS}

\subsection{Study area}

We chose to conduct our research in the Maine Lakes and Mountains tourism region in Western Maine due to the economic importance of winter tourism to communities [17] and because it experiences higher visitation in winter months [14]. The area is home to Maine's most visited ski resorts; winter activities include Nordic skiing, snowshoeing, ice fishing, and 
snowmobiling. Other nature-based attractions include hiking, biking, canoeing and kayaking, boating, fishing, fall foliage viewing, hunting, wildlife viewing, and camping.

\subsection{Methodology}

The data presented here were part of a larger project studying climate change risk perceptions in Western Maine's nature-based tourism industry in the summer of 2016 via semi-structured phenomenological interviews with 19 nature-based tourism stakeholders. Participants were selected using snowball sampling whereby participants recommended other potential participants until data saturation was achieved [18]. Nineteen pile sorts were conducted faceto-face as part of the interviews that were transcribed verbatim [19]. Participants were provided with 34 cards, each containing an environmental (17) or social condition (17) subject to variability as a result of climate change.

We used a structured, unconstrained pile sort approach where participants were given the same 34 cards, which were shuffled in between exercises, and asked to sort them into however many piles they wanted [5], [20]. The only criterion given was that terms should be placed in piles according to similarity and differences. After piles were constructed, participants were asked to name each pile and describe why they sorted the terms into their respective piles. Piles were photographed and the explanation of the sorting process was recorded as part of the interview and transcribed verbatim.

\subsection{Statistics}

The goal of pile sorting is to understand a cultural domain or group cognition or "what goes with what" [5]. To accomplish this goal, we used multidimensional scaling (MDS) to create a spatial map of how terms are related [5]. Data were analyzed using SPSS 23. Data were first entered into a two-dimensional matrix using Excel (Table 1). MDS plots were generated in SPSS to assess stress levels and dimensionality. Stress levels are recorded in Table 2 for 2, 3, and 4 dimensions. Pile names and participant description of pile sorting thought processes were analyzed in NVivo Pro 11 $\mathrm{C}$ to understand what conceptual lens participants were using when sorting items [21].

\section{RESULTS}

The total number of piles entered into SPSS was 116. On average, participants sorted the 34 items into six piles, with the number ranging from 3 to 10 piles. As previously stated, a stress value of 0.1 or less is considered to be excellent, while a stress value over 0.15 is unacceptable [6]. With these values in mind, in addition to the difficulty in interpreting more than two dimensions and the limited usefulness of such interpretations, we selected the two-dimension solution (Fig. 1). Upon reviewing the names participants gave their piles and analyzing their explanations, we determined "perceived control" as the x-axis dimension and "scale of impacts" as the y-axis dimension of the MDS plot. Table 3 lists the nine lenses used by participants when sorting items.

Six participants included piles that related to perceived levels of control. Naturally occurring phenomena were described as those that were not caused or impacted by human behavior, and therefore were seen as more difficult to control. Naturally occurring phenomenon included climate change and resulting impacts, such as changes in the amount of snow and rain, and rising sea level. Participants associated impacts caused by anthropogenic actions with higher levels of perceived control. For most participants, impacts were either caused by humans or were naturally occurring. 
Table 1: Pile sort data coding example.

\begin{tabular}{ccccccc}
\hline Participant & Pile & No. Cards & Item $\mathbf{1}$ & $\boldsymbol{\rightarrow}$ & $\boldsymbol{\rightarrow}$ & Item 34 \\
\hline $\mathbf{1}$ & 1 & 11 & 0 & 0 & 0 & 1 \\
$\mathbf{1}$ & 2 & 5 & 1 & 0 & 0 & 0 \\
$\mathbf{1}$ & 3 & 18 & 0 & 1 & 1 & 0 \\
$\mathbf{2}$ & 1 & 10 & 0 & 0 & 0 & 1 \\
$\mathbf{2}$ & 2 & 9 & 1 & 1 & 0 & 0 \\
$\mathbf{2}$ & 3 & 6 & 0 & 0 & 0 & 0 \\
$\mathbf{2}$ & 4 & 9 & 0 & 0 & 1 & 0 \\
$\mathbf{3}$ & 1 & 3 & 0 & 1 & 1 & 0 \\
\hline
\end{tabular}

Table 2: Multidimensional scaling results by number of dimensions.

\begin{tabular}{lcc}
\hline Model & Stress & Improvement \\
\hline 2 dimensions & 0.1031 & - \\
3 dimensions & 0.0489 & 0.0542 \\
$\mathbf{4}$ dimensions & 0.0293 & 0.0196 \\
\hline
\end{tabular}

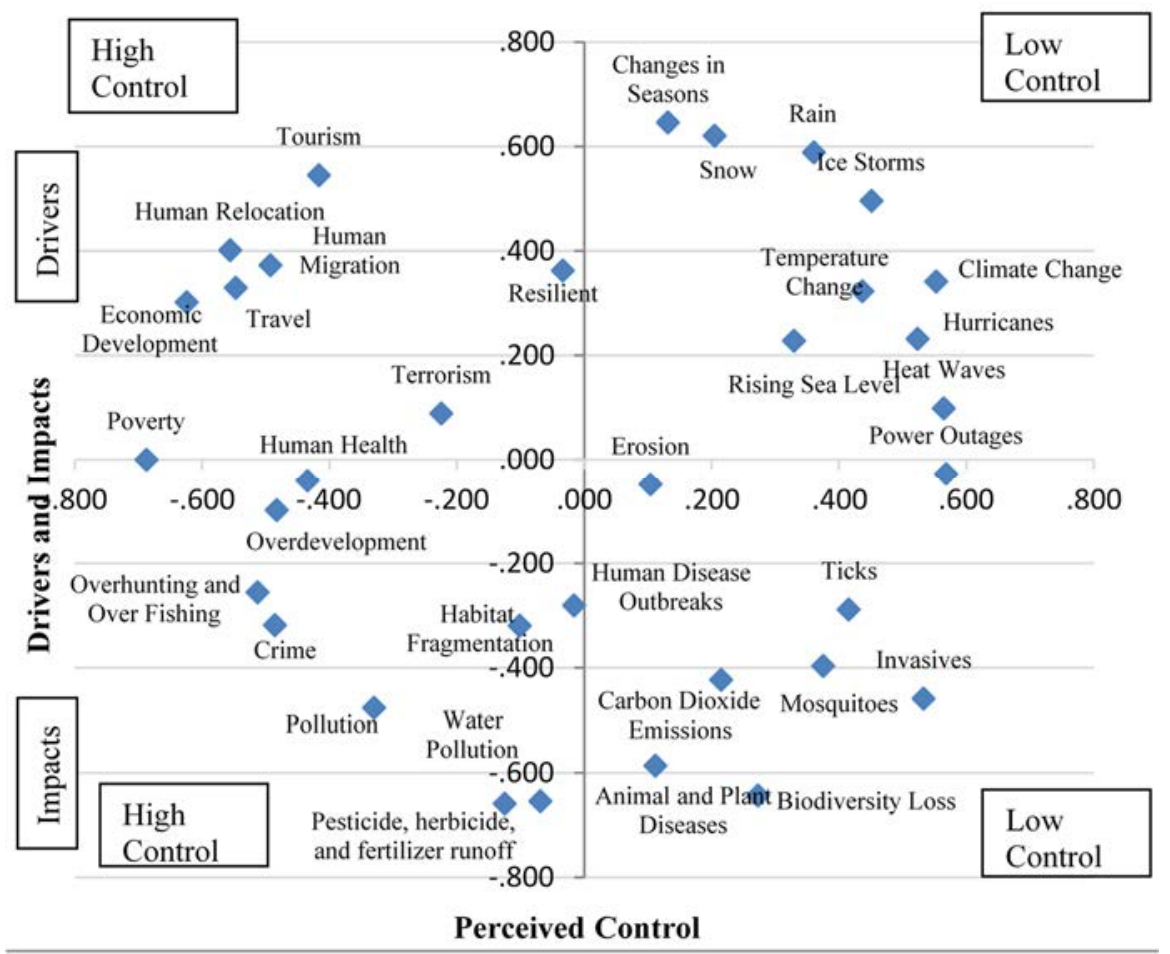

Figure 1: 2-Dimensional model solution. Toward the right of the plot, items were viewed as naturally occurring, indicating a low level of perceived control. Participants described items on the left as being human-caused, and therefore more controllable. Items on the top half of the MDS plot were described as drivers of Dimension 1: perceived control. 
Table 3: Summary of conceptual lenses and examples of associated pile names from participant interviews.

\begin{tabular}{|c|c|c|}
\hline Conceptual Lens & Frequency & Pile Name Examples \\
\hline Perceived Control & 6 & $\begin{array}{l}\text { "Factors that Impact Us But Can't Be } \\
\text { Controlled" } \\
\text { "Daily Impacts We Can Control" } \\
\text { "All Going to Happen No Matter What" }\end{array}$ \\
\hline Drivers and Impacts & 16 & $\begin{array}{l}\text { "Cumulative Effect of Unmanaged Human } \\
\text { Populations" } \\
\text { "Positive Impacts of Good Tourism } \\
\text { Development" } \\
\text { "Daily Impacts" }\end{array}$ \\
\hline Humans or Environment & 6 & $\begin{array}{l}\text { "Environmental Issues" } \\
\text { "The Human Condition" } \\
\text { "Social" }\end{array}$ \\
\hline Economic Development & 9 & $\begin{array}{l}\text { "Economic Development" } \\
\text { "Effects of Economic Development" }\end{array}$ \\
\hline $\begin{array}{l}\text { Happening Here, } \\
\text { Happening Elsewhere }\end{array}$ & 5 & $\begin{array}{l}\text { "Specific to Us" } \\
\text { "Happening Elsewhere" }\end{array}$ \\
\hline Weather & 3 & "Weather" \\
\hline Health Implications & 3 & "Health" \\
\hline Time & 1 & "Long-Term" \\
\hline
\end{tabular}

To the left side of the plot, items related to human actions were seen as slightly more controllable. One participant, Colleen (participant names have been changed to protect confidentiality), sorted cards into a pile where perceived control was high with two piles labeled "Daily Impacts: We Can Control" and "We Can Control but don't do Very Well." Colleen was involved in agritourism and spoke about how her operation can control impacts such as animal and plant disease outbreaks, carbon dioxide emissions, and water pollution. Colleen acknowledged that while she can personally control her agritourism business, she has no control over impacts from neighboring businesses. This resulted in varying levels of perceived control.

All six participants who used perceived control as a criterion for the pile sort exercise had piles indicating low levels of perceived control. The terms in these piles were often acknowledged to be caused and influenced by humans but participants felt that these issues were out of their control to manage or influence. One participant described how he was personally experiencing some of the pile sort items but felt that one person could not make a difference in effectively reducing these impacts. This was a sentiment shared by several other participants who described phenomena such as climate and temperature change as global problems with little perceived control in being able to reduce the local impacts of these conditions. Participants felt unable to lessen the impacts of these conditions and only able to react or adapt to them, resulting in a low level of perceived control; however, one participant included "resilient" in her "Things We Bring upon Ourselves" pile.

I guess I sort of feel that, I guess this pile is kind of related in terms of, these are things that we bring on ourselves...Resilient. We need to be able to adapt to whatever changes come our way, you know? (Angela, Regional Manager). 
What starts out as a tentative placement of "resilient" ultimately becomes its final categorization. She justifies her decision by saying that a state of community or tourism destination level resilience is created by humans' abilities to adapt to changes, and therefore is within the control of the community. Even though human actions result in negative environmental outcomes, humans' actions are also capable of positively impacting the community and tourism destination, such as increased resilience through adaptation.

\subsection{Dimension 2: drivers and impacts}

Participants sorted items into piles noting the drivers and resulting environmental impacts, both positive and negative, to either the tourism or overall social-ecological system. Participants often differentiated between human drivers and environmental drivers of change. Several participants created "Weather" piles and went on to explain the connection between drivers, such as climate change, and impacts, such as warming temperatures. Most participants listed human behaviors as resulting in harmful impacts to both environment and society.

Similarly to "Weather", several participants created piles entitled "Climate Change" or "Related to Climate Change." When asked to explain their thinking behind sorting terms, these participants went on to describe the drivers of climate change impacts.

Just looking at those as macro drivers, climate change, driven by carbon dioxide emissions, leading to increased temperatures, leading to changes in seasons. From there, there's a whole series, you know from changes of seasons that has influence on weather patterns, ice storms, hurricanes, sea level, erosion, snow, all those things I would see as linked to climate and changing seasonal patterns (Thomas, Regional Manager).

This participant then went on to list impacts driven by climate change. Interestingly, most participants who developed piles associated with climate change were able to list resulting impacts; however, not as many participants described the drivers or causes of climate change.

Of the participants who discussed causation of climate change, two acknowledged human behaviors as drivers of climate change. Four participants created a pile specific to climate change and did not choose either human or natural causation. The remaining two participants were uncertain about drivers of climate change. In contrast, most participants were able to confidently identify impacts of climate change. The majority of participants who used these criteria distinguished between impacts driven by human actions and those that occurred naturally outside of human influence. There were few instances where participants described mixed drivers where a phenomenon could exist naturally but be caused also by human actions. Overall, participants focused on sorting terms into drivers and resulting impacts of environmental change, but did not specifically focus on drivers and impacts of climate change.

\section{DISCUSSION}

Participants who used perceived control to label their piles generally felt as though they lacked control over many card items. Participants distinguished between human and natural causation, which were associated with higher and lower perceived levels of control respectively. Human actions were seen as largely negatively impacting the environment.

Perceived behavioral control refers to an individual's perceived capability at successfully engaging in a behaviour, and is represented by perceived efficacy - the belief that one's actions make a difference - and controllability - the extent of control [22]. Participants 
generally expressed low levels of control, especially over events that were perceived as naturally occurring, such as loss of biodiversity, increases in tick populations, and changes in specific climate variables. Previous research has indicated that perceived behavioral control may be especially important in predicting behavior when participants feel they do not have conscious control over a phenomenon [22], [23]. This could mean that the low perceived control expressed by participants might be an important factor when deciding to respond to climate change.

The low levels of perceived control and self-efficacy may pose a barrier to climate change mitigation and adaptation strategies [24]. Climate change is often thought of as being beyond the capability of one individual to deal with; this idea was shared by several participants. This sentiment is in keeping with other studies that have found climate change to be a global problem and because of its vast scope, many people feel that they as individuals can do little to fix the problem [23], [24]. Our research suggests that many participants are uncertain about the causes and drivers of climate change and feel as though addressing climate change is out of their control. In combination with an incomplete understanding of the causes of climate change [24], low perceived control and low self-efficacy can inhibit stakeholders from addressing stressors that they may be able to influence through individual or collective action. Milfont [23] found that higher self-efficacy can be related to higher levels of concern, perceived risk, and environmental engagement. Previous studies have also found a positive connection between knowledge of climate change, self-efficacy, and willingness to help address climate change [23], [25]. The low perceived control expressed by participants could result in limited or no mitigation behaviors if participants do not think their behaviors have any influence on global phenomena. Our findings indicate that participants did not fully understand drivers of climate change and expressed low perceived control in their ability to influence both climate change drivers and impacts.

Increasing participants' feelings of perceived control and self-efficacy could help foster mitigation and adaptation strategies [25]. A study of UK residents found that lack of knowledge, uncertainty or skepticism, fatalism, helplessness, and lack of enabling initiatives were all barriers preventing effective engagement with climate change [26]. Matasci et al. [27] identified similar barriers to climate change actions including a lack of knowledge regarding how the tourism destination is being impacted and the potential mitigation and adaptation strategies available to stakeholders. It appears that providing more climate change information, especially about local impacts [26] through trusted sources, could be a means to increase climate change mitigation and adaptation behaviors. Empowering Western Maine tourism stakeholders through increased knowledge could help increase perceived control and self-efficacy, thereby increasing behavioral intention to mitigate and adapt to climate change. Additionally, more knowledge of pro-environmental behaviors could help empower participants and increase perceived efficacy by exposing them to behaviors that they could adopt that would positively impact the environment [25].

Sorting items based on whether impacts were driven by humans or nature could influence perceived control among participants and may help determine willingness to act. Previous research has found that people are more willing to reduce environmental risks if they are caused by humans [28]. A survey of US residents found that belief in anthropogenic climate change was related to feelings of responsibility, which could translate into the adoption of adaptation and, especially, mitigation behaviors [29]. Understanding the combination of environmental and anthropogenic drivers could help empower tourism stakeholders in Western Maine to take action to reduce their climate impact. For example, understanding the causes of climate change, both natural and human drivers, could help participants make connections between their own actions and broader environmental phenomena [26]. 
Pile sorting has broad applications and could be a powerful tool [5] to help address the need for a better understanding of how people think about climate change. Our results indicate that increasing perceived behavioral control amongst tourism stakeholders could encourage mitigation and adaptation behaviors. Participants felt that they had very little control over climate change. Participants also made connections between human and environmental drivers and resulting impacts. Very few participants acknowledged that environmental and anthropogenic drivers could work together to create impacts. Providing tourism stakeholders with more information about climate change causes, impacts, and potential solutions could be a strategy to increase knowledge of drivers and impacts and increase perceived behavioral control, leading to more pro-environmental action.

\section{ACKNOWLEDGEMENTS}

The authors would like to thank all interview participants and gatekeepers for sharing their time and perspectives for this research. We would like to acknowledge funding from the USDA National Institute of Food and Agriculture, McIntire-Stennis, and by University of Maine Office of the President.

\section{REFERENCES}

[1] Cramer, W. et al., Detection and attribution of observed impacts. Climate change 2014: impacts, adaptation and vulnerability. Part A: global and sectoral aspects. Contribution of Working Group II to the Fifth Assessment Report of the Intergovernmental Panel on Climate Change, pp. 979-1037, 2014.

[2] Climate Change and Tourism, UNWTO, http://sdt.unwto.org/en/content/climatechange-tourism. Accessed on: 30 Mar. 2017.

[3] Shakeela, A. \& Becken, S., Understanding tourism leaders' perceptions of risks from climate change: an assessment of policy-making processes in the Maldives using the social amplification of risk framework (SARF). Journal of Sustainable Tourism, 23(1), pp. $65-84,2015$.

[4] Jordan, E. \& Javernick-Will, A., Measuring community resilience and recovery: A content analysis of indicators. Construction Research Congress 2012: Construction Challenges in a Flat World, pp. 2190-2199, 2012.

[5] Bernard, H.R., Research Methods in Anthropology: Qualitative and Quantitative Approaches (5th ed.), Altamira Press: Walnut Creek, CA, pp. 299-318, 2011.

[6] Borgatti, S.P., Elicitation Techniques for Cultural Domain Analysis. http://steveborgatti.com/papers/bhetk.pdf. Accessed on: 13 Oct. 2016.

[7] Weller, S. \& Romney, A.K., Systematic Data Collection. SAGE Publications: Thousand Oaks, CA, pp. 9-31, 1989.

[8] Novais, G. \& Câmara, V. de M., Perception of mercury contamination by Brazilian adolescents in a gold mining community: an ethnographic approach. Ciência \& Saúde Coletiva, 14(6), pp. 2015-2026, 2009.

[9] Longfield, K., Rich fools, spare tyres and boyfriends: Partner categories, relationship dynamics and ivorian womens risk for STIs and HIV. Culture, Health, and Sexuality, 6(6), pp. 483-500, 2004.

[10] Miller Hesed, C.D. \& Paolisso, M., Cultural knowledge and local vulnerability in African American communities. Nature Climate Change, 5(7), pp. 683-687, 2015.

[11] Stone, D. et al., The challenge to detect and attribute effects of climate change on human and natural systems. Climatic Change, 121(2), pp. 381-395, 2013. 
[12] Verbos, R.I., Altschuler, B. \& Brownlee, M.T.J., Weather studies in outdoor recreation and nature-based tourism: a research synthesis and gap analysis. Leisure Sciences, DOI: 10.1080/01490400.2017.1325794, 2017.

[13] Maine Office of Tourism, Maine Office of Tourism Visitor Tracking Research: 2017 Calendar Year Annual Report. https://visitmaine.com/assets/downloads/2016 MOT_AnnualReport.pdf. Accessed on: 1 Jun. 2017.

[14] Maine Office of Tourism, Maine Office of Tourism Visitor Tracking Research: 2015 Calendar Year Annual Report. http://visitmaine.com/assets/downloads/2015 AnnualReport.pdf. Accessed on: 1 Nov. 2015.

[15] Carrillo, M., De Urioste-Stone, S.M. \& Le, L., Economic Impact of Nature-based Tourism in Maine, University of Maine: Orono, ME, 2017.

[16] Fernandez, I.J. et al., Maine's Climate Future. University of Maine: Orono, ME; 2015.

[17] Wilkins, E., De Urioste-Stone, S., Weiskittel, A. \& Gabe, T., Effects of weather conditions on tourism spending: implications for future trends under climate change. Journal of Travel Research, https://doi.org/10.1177/0047287517728591, 2017.

[18] Patton, M., Qualitative Research \& Evaluation Methods: Integrating Theory and Practice (4th ed.). SAGE Publications: Thousand Oaks, CA, pp. 244-287, 2015.

[19] Kowal, S. \& O'Connell, D.C., Transcription as a crucial step of data analysis. The SAGE Handbook of Qualitative Data Analysis, ed. U. Flick, SAGE Publications: Thousand Oaks, CA, pp. 64-78, 2014.

[20] Quintiliani, L.M., Campbell, M.K., Haines, P.S. \& Webber, K.H., The use of the pile sort method in identifying groups of healthful lifestyle behaviors among female community college students. Journal of American Dietetic Association, 108(9), pp. 1503-1507, 2008.

[21] Seekamp, E., Cerveny, L.K. \& McCreary, A., Institutional, individual, and sociocultural domains of partnerships: A typology of USDA Forest Service recreation partners. Environmental Management, 48(3), pp. 615-630, 2011.

[22] Shrestha, S.K. \& Burns, R.C., Integrating constraints to the theory of planned behavior in predicting deer hunting participation. Human Dimensions of Wildlife, 21(5), pp. 445-459, 2016.

[23] Milfont, T.L., The interplay between knowledge, perceived efficacy, and concern about global warming and climate change: A one-year longitudinal study. Risk Analysis, 32(6), pp. 1003-1020, 2010.

[24] Gifford, R., The dragons of inaction: Psychological barriers that limit climate change mitigation and adaptation. American Psychologist, 66(4), p. 290, 2011.

[25] Ung, M., Luginaah, I., Chuenpagdee, R. \& Campbell, G., Perceived self-efficacy and adaptation to climate change in coastal Cambodia. Climate, 4(1), pp. 1-16, 2015.

[26] Lorenzoni, I., Nicholson-Cole, S. \& Whitmarsh, L., Barriers perceived to engaging with climate change among the UK public and their policy implications. Global Environmental Change, 17(3-4), pp. 445-459, 2007.

[27] Matasci, C., Kruse, S., Barawid, N. \& Thalmann, P., Exploring barriers to climate change adaptation in the Swiss tourism sector. Mitigation and Adaptation Strategies for Global Change, 19(8), pp. 1-16, 2013.

[28] Baron, J., Thinking about global warming. Climatic Change, 77(1-2), pp. 137-150, 2006.

[29] Bateman, T.S. \& O'Connor, K., Felt responsibility and climate engagement: Distinguishing adaptation from mitigation. Global Environmental Change, 41, pp. 206-215, 2016. 